\title{
Knowledge life cycles inside local economic systems*
}

Forthcoming in P. Cooke and A. Piccaluga, Regional Development in the Knowledge Economy (Routledge, forthcoming).

\section{Lucio Poma}

Università degli Studi di Ferrara - Facoltà di Economia

Ciras - International Research Centre for Environment and Development

Via del Gregorio 13 - 44100 Ferrara - Italy

and Antares - Reserch Centre for Industrial and Territorial Economics

1.poma@economia.unife.it

Phone: +390532293044

Fax: +390532293012

Silvia Sacchetti (address for correspondence)

Università degli Studi di Ferrara - Facoltà di Economia

Institute for Industrial Development Policy (L'institute)

Via del Gregorio 13 - 44100 Ferrara - Italy

and Antares - Reserch Centre for Industrial and Territorial Economics

sacchetti@economia.unife.it

Phone: +390532293044

Fax: +390532 293012

Mobile: +393332957293

\begin{abstract}
Our paper addresses the mechanisms that favour the production, re-production and diffusion of knowledge within firms and territories. The analysis is set around two main ideas: one concerned with the relationship between knowledge dynamics, firms and local economic systems, the other explaining knowledge dynamics inside firms. We introduce the new concept of knowledge life cycles, which aims at capturing declining and ascending flows of knowledge. Our main finding is that knowledge does not always follows a cumulative process, but it can evolve or stagnate and, if not renewed, it can be subject to a process of decay. We support the theoretical analysis with surveys undertaken in two Italian provinces.
\end{abstract}

\footnotetext{
* This paper builds on previous works of the authors, in particular: Poma (2003) and Sacchetti (2003). The empirical work relies on original data that belongs to Antares (Research Centre for Industrial and Territorial Policy) where Lucio Poma is president and Silvia Sacchetti researcher. We would like to thank the participants to the Pisa Regional Studies Association Annual Conference for comments and suggestions. We would also thank Assindustria Reggio-Emilia. We are especially grateful to Lorenzo Ciapetti and Antares research fellows who have actively contributed to the empirical research projects to which we refer in this work.
} 


\section{PRODUCTION SYSTEMS AND KNOWLEDGE}

Within production systems, knowledge is important for a number of reasons: it confers value to products, it generates innovative dynamics, it simulates technological development, it creates competitive advantages, it favours the creation of relations amongst economic actors, and attracts activities. As a consequence, nowadays knowledge can be seen as one of the most significant elements for the competitiveness of advanced economies and, in particular, of local production systems.

We keep our focus on those aspects of the relationship between knowledge and the economy that are related to production. We approach a particularly vast concept, which can refer to the knowledge incorporated inside technologies, human capital, firms, networks of firms, or within linkages amongst firms and other actors on the territory. Knowledge can be the outcome of past experiences, the fruit of intuition and research, the result of the imitation of secrets of production. Knowledge can be contextual, or the tacit capacity which derives from specialisation and successful experiences. In parallel, knowledge is subject to diffusion: amongst individuals, organisations, within a locality or between different territorial systems.

When talking about knowledge in production, the core dimension is the relationship between tacit knowledge, which involves human resources on the one hand, and the knowledge codified inside production machineries and technical manuals on the other. If in Smith's (1776) analysis the main focus is on manufacture, for which human skills and the tacit knowledge of the craftsman are fundamental. Subsequently, in the work of Marx (1867) the machine becomes the core of production and the sphere of action of individuals shifts from that of physical production to the organisation, the co-ordination and control of machineries. ${ }^{1}$ Increasingly, production becomes related to the design, organisation and control of machines: it shifts from physical production to the production of knowledge (Pollock, 1957; Kern and Schumann, 1984)..

If Smith centred his analysis on manufacturing and Marx and Taylor on the factory, today the complexity which characterises production activities pushes an enquiry about knowledge beyond a strict focus on machines and human resources. Linkages amongst

\footnotetext{
${ }^{1}$ For a Marxist perspective on the impoverishment of workers' capacity caused by the division of labour, see Braverman (1974).
} 
firms and between firms and institutional actors become important knowledge repositories as well. Past and future receive a different meaning with respect to common connotations. We link past to the knowledge settled inside the firm; on the other side we see future as the capacity of a firm to generate new knowledge. This capacity develops along two directions. We call the first the adaptive function of firms, meaning that the capacity to create new knowledge is functional to an understanding of the evolving socio-economic phenomena with which the firm must interact. The firm adapts its internal organisation and knowledge to exogenous changes. We name the second connotation innovative function. In this case, the capacity to generate knowledge is functional to the ability to plan and design new production and organisational opportunities as well as to increase competitiveness. In this case, the firm is not a follower but a proactive actor of change.

\section{TACIT AND CODIFIED KNOWLEDGE}

Most of our actions depend, for their achievement, on our knowledge. We can see this knowledge as composed by a sub-group of knowledge, of which the individual is aware when acting, and by a vast sub-group of knowledge of which individuals are not conscious. This second set is tacit knowledge (Polanyi, 1958). By doing things the individual acquires practical knowledge and through a process of trials, errors and adjustments he/she memorises the sequence of actions that steered him/her successfully to his/her objective. This sedimentation of 'memory' forms tacit knowledge.

Codified knowledge represents an extrapolation of tacit knowledge which occurs when the latter is 'translated' and fixed inside manuals or incorporated by machineries. Codified knowledge is the language through which knowledge transfer occurs. Craft enterprises and more generally small firms are principally built on tacit knowledge, whilst as size increases firms transfer mainly codified and standardised knowledge.

Codified knowledge can be transmitted more rapidly. Its main limitation is that it does not allow to transfer all the capital that is included inside tacit knowledge. Large firms, by virtue of their scale and standardisation of production need to rapidly instruct labour and therefore they will mainly transfer codified knowledge. Oppositely, small firms and craft firms rely essentially on tacit knowledge. Although with different intensity, we can 
find both the components of knowledge, tacit and codified, in the large as well in the small firm.

\subsection{Some empirical evidence}

The results of a recent research undertaken in the Italian province of Reggio Emilia (Emilia-Romagna) seem to support some of the above mentioned hypotheses. Firms have been classified according to the $R \& D$ intensity that characterises sectors. In particular, Pavitt (1984) provides criteria to classify firms on the basis of the attitude of a sector to produce innovation. Inside certain industries firms ask for the technology produced by other sectors. Others, conversely, mainly rely on their internal R\&D. According to this criteria, together with Pavitt (1984), we classify firms using the following four categories: "supplier dominated" (SD), "scale intensive" (SI), "specialised suppliers" (SS) e "science based" (SB). ${ }^{2}$

We found out that firms belonging to SS sectors are particularly oriented towards hiring managers with a university degree. Therefore, sectors such as those producing control equipment or specific high-tech components for other firms favour the introduction of individuals with a strong codified knowledge base, provided in this case by education. In parallel, a corresponding amount of firms hires managers without a university degree. This result suggests the existence of industrial realities for which the degree of complexity that characterises a sector does not require high levels of codified knowledge (as a university degree can be), but encourage individual learning inside the firm, in some cases with the help of training programmes.

\footnotetext{
${ }^{2}$ We interviewed 168 firms, mostly manufacturing, and with a size above the Italian average size measured by the number of employees. See Appendix A).
} 
Figure 1: Average number of years that are necessary for the training of a manager by Pavitt categories

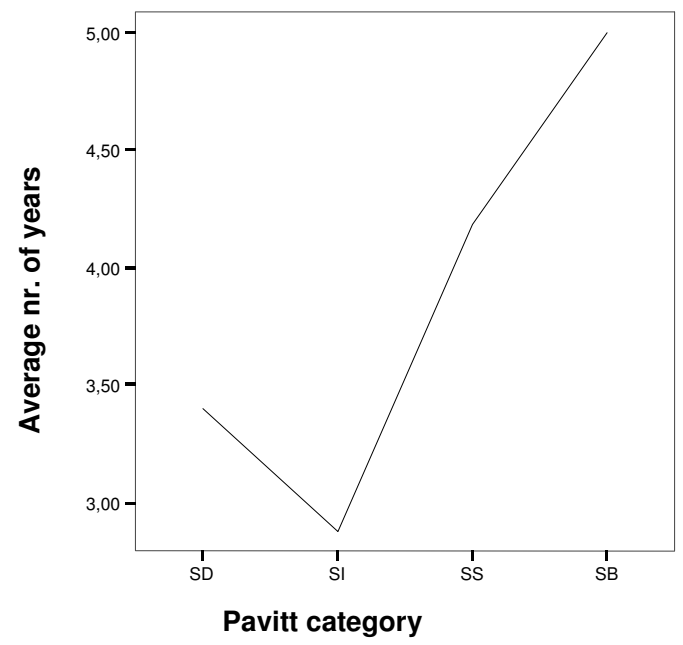

The learning process which brings managers to knowledge maturity takes, on average, three years for SD and SI sectors, whilst it takes more time for SS e SB sectors (four and five years, respectively). These results suggest that in sectors where knowledge and complexity evolve more rapidly, managers need to improve their individual knowledge through a learning process which is based also on experience and on the skills acquired inside the firm.

The presence of people with university degrees is important for the industrial development of a territory because it increases the possibility for firms to catch new technological or market opportunities. However, the Italian production system is not entirely able to capitalise this fundamental resource. The percentage of firms that, during the last five years, have hired executives and white-collars workers with a university degree is $43 \%$. Until twenty years ago these tasks were targeted by workers with secondary education. In parallel, $79 \%$ of firms has experienced difficulties in finding specialised workers and technicians.

On the face of these results, firms seem to confront with a bottle neck which is not caused by the impossibility to access workers with the highest education, but individuals with specific technical competences or, in other words, people who are able to use technologies. 
The length of the training period of workers with specific technical competences, in particular, varies according to the size of firms. We observe that firms invest in the training of skilled blue collars a period which goes, on average, from a bit less than two years to two years and half.

Figure 2: Relation between firm's size class and the average number of years to reach knowledge maturity for a skilled blue collar

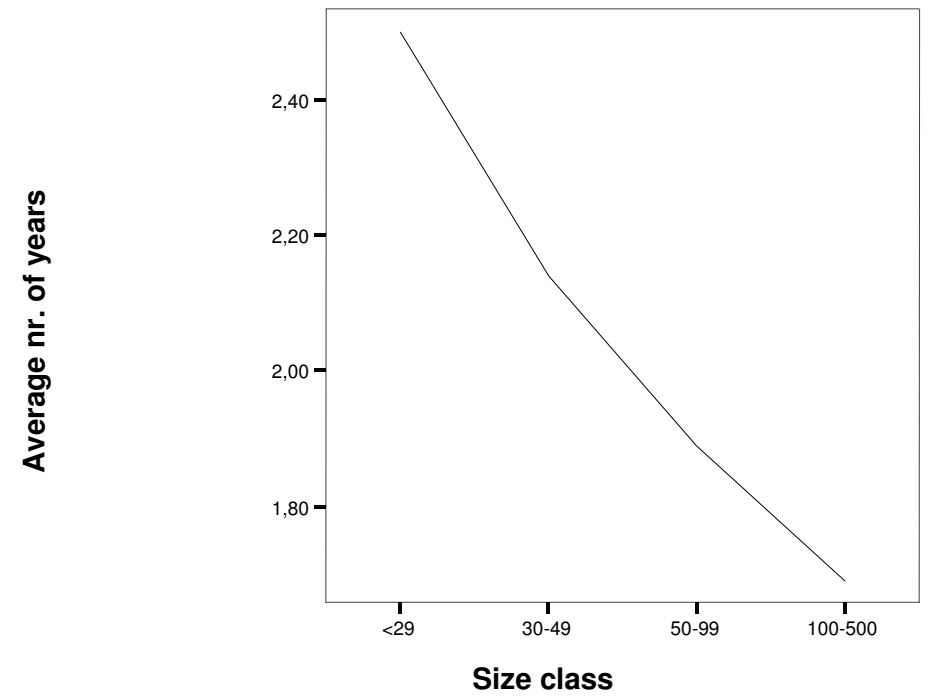

In particular, if we consider the first four dimensional classes, those including firms up to 500 workers, we observe a strong inverse correlation $(-0.88)$ between the learning period and the size of the firm. The difference between small firms ( $<29$ employees) and larger firms (100-500) is remarkable: the learning period for a specialised blue collar in firms with less than 29 employees lasts $50 \%$ more than the learning period required inside firms with 100-500 employees.

We read these results on the face of the smithian principle of the division of labour: as the size of the firm increases, individuals adapt to an increasingly focused functional specialisation, which requires, as the division of labour augments, shorter learning periods. This result is consistent with what we have noticed before with respect to tacit and codified knowledge: as larger firms relies more than smaller firms on the specificity of tasks and on codified knowledge, individual knowledge is more focused and can be 'transferred' more rapidly than tacit knowledge. 
At the same time, what we have observed so far has to be linked to the different degrees of complexity and to the different levels of ability and skills that characterise various sectors and functions. In Table 1 we relate the length of the learning period of a skilled worker with the nature of the sector. Results support the hypothesis that we have advanced: firms operating in SI sectors require shorter learning periods. In parallel, in labour intensive sectors (those defined as SD) the maturation of a skilled blue collar takes longer. The highest number of years is needed, on average, for specialised suppliers (SS) where we find firms producing technologies and products which requires internal competences in design and development.

Table 1: Average number of years to reach knowledge maturity for a skilled blue collar by Pavitt category

\begin{tabular}{|cc|}
\hline Pavitt category & Number of years \\
& \\
\hline SD & 2,4 \\
\hline SI & 1,6 \\
\hline SS & 3,0 \\
\hline SB & 2,3 \\
\hline Average & $\mathbf{2 , 3}$ \\
\hline
\end{tabular}

These results emphasise the importance of the tacit and codified nature of knowledge that belongs to a skilled worker for all dimensional classes: learning lasts for two years on average. The incidence of longer learning periods inside smaller firms, which are mainly labour intensive firms belonging to SD sectors, may be linked to what we were arguing before: tacit knowledge characterises especially small firms. Indeed, consistent levels of tacit knowledge may be acquired only by accumulating experience and specific learning. This process requires time. The time needed to transfer knowledge, here meant as transmission of skills, dexterity and judgment, is linked to the degree of division of labour and to the innovative characterisation of the sector.

Evidences of the relationship between codification of knowledge and the size of the firm come also from data on R\&D centres (Figure 3). Our empirical work has shown a strong correlation (0.94) between the size of the firm and R\&D centres inside firms. The 
frequency of firms with an internal R\&D centre increases as size augments. From $8.5 \%$ of firms with less than 30 employees, frequencies shift to $48 \%$ for firms with $100-500$ employees and to $100 \%$ for firms with more than 500 employees.

Figure 3: Relationship between internal R\&D and firm size - Frequencies within size class $(\%)$

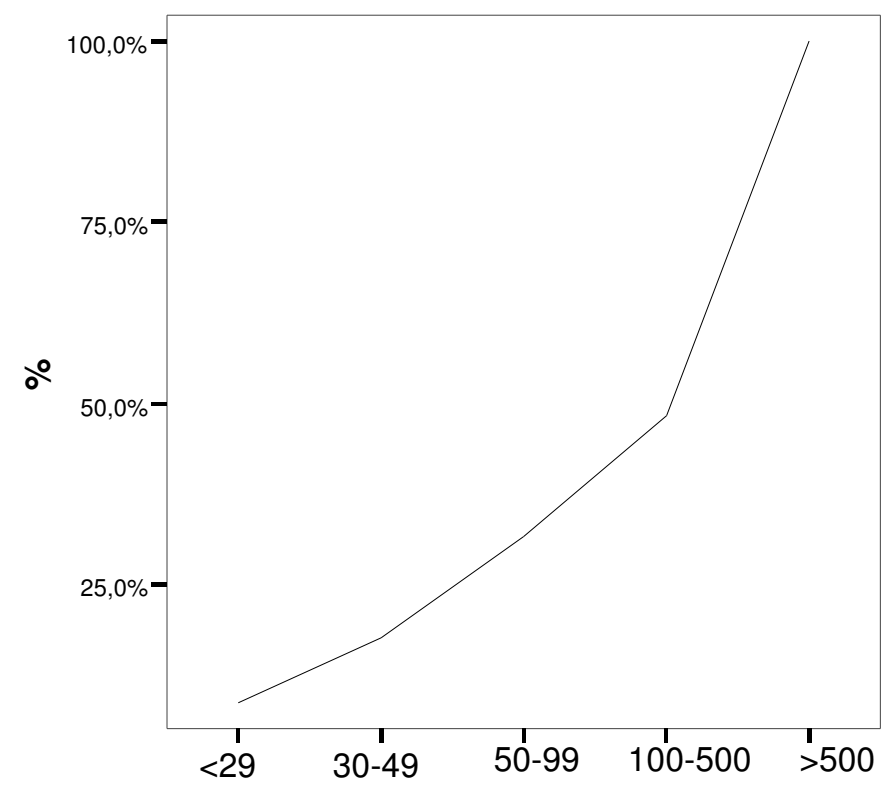

\section{KNOWLEDGE PRODUCTION}

Inside a closed economy the 'institutional spaces' of production and exchange tend to overlap. As markets open these two institutional spaces are increasingly diverging. Competition does not occur only through techniques and technologies, but puts side by side and compare different institutional contexts in different countries. This widened competitive environment is one of the factors which has contributed to design a new international division of labour. Advanced economies are experiencing the difficulty to compete on costs against economic and institutional contexts where salaries are kept at the level of subsistence. Therefore, firms in advanced economies are obliged to improve 
the quality of their production, augmenting the value added and emphasising the 'knowledge value' incorporated by goods or services. Physical production is the outcome of the institutional context where knowledge circulates. The tacit element of this knowledge surfaces and flows inside new information and communication technologies.

Knowledge is produced by firms but also by the whole territorial system. The production of knowledge is not a natural and casual event but it is strictly related to the institutional context where knowledge develops and consolidates: knowledge production is part of a 'project' that must be stimulated and governed. The capacity of a country, of its regions and local systems to interpret and stimulate knowledge production determines the conditions and the modalities of competition, as well as the position of these territorial systems inside new production dynamics ${ }^{3}$

A new role for knowledge appears. Knowledge is not a complementary element incorporated by skills, it is not reduced to learning by doing or learning by using, but it is the engine of development. It is the creation of knowledge which provides the tools to interpret economic complexity and uncertainty. This has induced advanced economies to a transition from physical production, which implicitly wells up from knowledge, typical of Fordism and partly of post-Fordism, to the explicit production of knowledge.

Table 2 shows the evolution of entrepreneurs' investment expectations in the province of Reggio Emilia. ${ }^{4}$ In particular, the first three typologies of investments (research and product innovation, computer and software systems for business, computer and software systems for production activities) identify investments in intangibles, whilst the remaining typologies refer to physical capital.

\footnotetext{
${ }^{3}$ For an analysis of the impact of different forms linkages amongst firms Cf. Sacchetti and Sugden (2003).

${ }^{4}$ Data collected during a seven year survey on a sample of 120 firms.
} 
Table 2: Percentage of actual investments on expected investments, Province of Reggio Emilia 1994-2000

\begin{tabular}{|c|c|c|c|c|c|c|c|}
\hline Type of Investment & 1994 & 1995 & 1996 & 1997 & 1998 & 1999 & 2000 \\
\hline $\begin{array}{l}\text { Research and product } \\
\text { innovation }\end{array}$ & $103 \%$ & $49 \%$ & $203 \%$ & $117 \%$ & $59 \%$ & $139 \%$ & $89 \%$ \\
\hline $\begin{array}{l}\text { Computer and software } \\
\text { systems for business }\end{array}$ & $117 \%$ & $103 \%$ & $236 \%$ & $169 \%$ & $105 \%$ & $206 \%$ & $125 \%$ \\
\hline $\begin{array}{l}\text { Computer and software } \\
\text { systems for production }\end{array}$ & $100 \%$ & $63 \%$ & $179 \%$ & $161 \%$ & $88 \%$ & $182 \%$ & $93 \%$ \\
\hline Enlargment of sites & $107 \%$ & $82 \%$ & $205 \%$ & $205 \%$ & $116 \%$ & $169 \%$ & \\
\hline $\begin{array}{l}\text { Enlargment of } \\
\text { production lines }\end{array}$ & $151 \%$ & $76 \%$ & $195 \%$ & $138 \%$ & $107 \%$ & $175 \%$ & $88 \%$ \\
\hline $\begin{array}{l}\text { Restructuring/conversion } \\
\text { of production lines }\end{array}$ & $91 \%$ & $80 \%$ & $134 \%$ & $126 \%$ & $106 \%$ & $3 \%$ & $95 \%$ \\
\hline New production lines & $89 \%$ & $45 \%$ & $131 \%$ & $163 \%$ & $90 \%$ & $0 \%$ & $83 \%$ \\
\hline Total investments & $98 \%$ & $65 \%$ & $180 \%$ & $129 \%$ & $84 \%$ & $131 \%$ & $102 \%$ \\
\hline
\end{tabular}

Source: authors' elaboration on data Assindustria Reggio Emilia (Industrial Association of Reggio Emilia)

Data indicates the ratio between investments at time $t$ (actual investments) and investments planned by firms the year before, at time $t-1$. The ratio shows which typologies have been over-estimated (percentage is below 100) and which, on the contrary, have required a larger commitment with respect to expectations (percentage is over 100). As far as intangibles are concerned, we observe important under-estimations since 1996. Investments in research and product innovation, in particular, is the more rising and falling typology. This stresses the delicate equilibriums of research outputs: planned investments for the realisation of specific projects could be interrupted before end when, for instance, unexpected difficulties arise during the research process. Differently, we observe that investments in ICTs (computer and software systems for business and production) are constantly under-estimated.

\subsection{Information and Communication Technologies (ICTs) and knowledge production}

The recognition of ICTs' relevance, recognised also by Agenda 2000, assumes a special meaning if we think about the massive presence of SMEs in the European industry. SMEs can be seen as the nodes of a thick network of relationship. The production of 
knowledge implies collective interaction amongst territorial actors. Production and its environment are not separated, they are two indissoluble dimensions, one is visible and includes physical production, the other is invisible and relates to the production of knowledge. The space of these interactions may be local, or it may go beyond regional and national borders. ICTs, with respect to the speed and flexibility of exchange, may facilitate co-operation. This increases information flows and improves the possibility to share information with remote actors through the creation of long-distance networks, for example to manage just-in-time systems or to co-design products at the distance.

\subsection{Some empirical evidence}

Results from our empirical research in Reggio-Emilia shows that $52 \%$ of firms uses ICTs to interact with other firms: $42 \%$ of users utilises EDI, whilst $16 \%$ rely on ERP. A crucial point that emerges from our analysis is that ICTs are perceived and used as accelerators of old production and organisational modalities rather than as radical technological changes that redefine production and the organisational context. In particular we have observed that firms in Reggio-Emilia do not exploit the communication potential (knowledge circulation) of ICTs, nor their project making potential (knowledge production). Indeed, 95\% of users relies on ICTs to communicate, $78 \%$ to transfer files. Both these two functions could be substituted by traditional technologies, such as the telephone or mail. Only one quarter of ICTs users apply ICTs to co-design products in partnership with other firms. ICTs are therefore a useful instrument to enhance the circulation of codified knowledge amongst firms, whilst the creation and design of products are undertaken according to traditional ways. 
Table 3: Objectives that are pursued with the use of ICTs

\begin{tabular}{|lc|}
\hline \multicolumn{1}{|c|}{ Motivation } & \% of user \\
& firms \\
\hline Communication & 95,1 \\
File transfer & 80,3 \\
To manage integrated process information & 36,1 \\
Co-design products & 26,2 \\
To accelerate post-sale services & 23,0 \\
To delegate customer services & 13,1 \\
To create new products in partnership & 8,2 \\
Other & 4,0 \\
\hline
\end{tabular}

ICTs brake with previous technological paradigms and imply a new codification of competences and knowledge. In terms of industrial organisation, the small firm owner has generally a deep knowledge of its machineries; he/she is able to adapt them to the productive process introducing incremental innovation as a distinctive action of SMEs. Moreover, he/she is also able to estimate the productivity of the machinery and assess the convenience of a new purchase. Technology dissemination policies focus, in this case, on information. The introduction of ICTs breaks down this mechanism. Knowledge must be codified anew. This can be done more easily by large enterprises where most of the knowledge is codified, rather than by small firms which are more used to tacit forms of knowledge. In the latter case, the entrepreneur may not have the capability to adapt his knowledge to the new paradigm.

Our territorial analysis has considered the entrepreneurs' perception of the magnitude of change introduced by ICTs. $32 \%$ of user firms reckons the essentiality of ICTs.

\section{Figure 4: Entrepreneurs' judgment on ICTs}

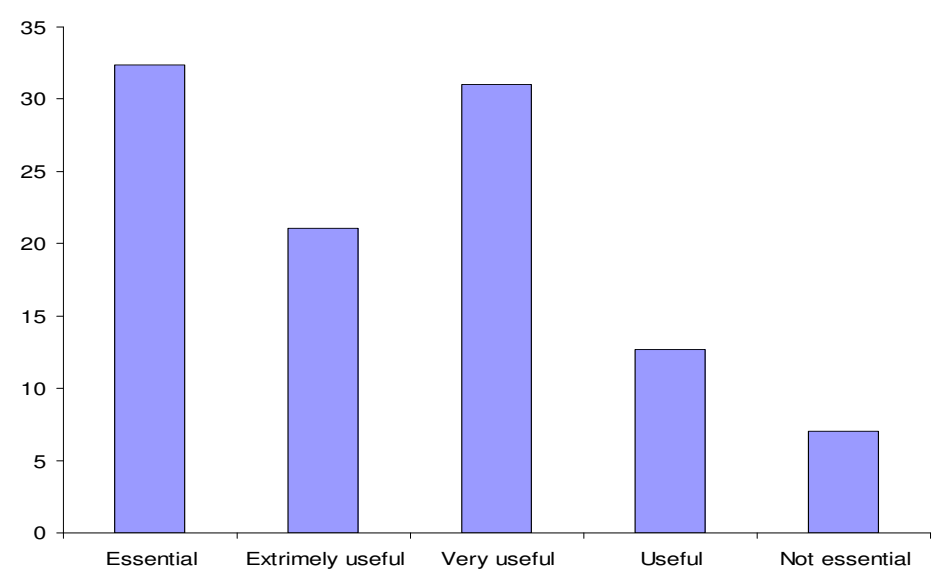


The declared essentiality of ICTs for inter-firm production relations suggests that for one third of firms these technologies are not juxtaposed to traditional communication technologies as an alternative, but they are conceived as opening new opportunities.

When the technological change induced by ICTs is followed by organisational change we can assume that firms will increase their productivity. $64 \%$ of user firms has indeed declared to have modified its structure as a consequence of ICTs.

\section{Figure 5: Organisational changes within ICT users}

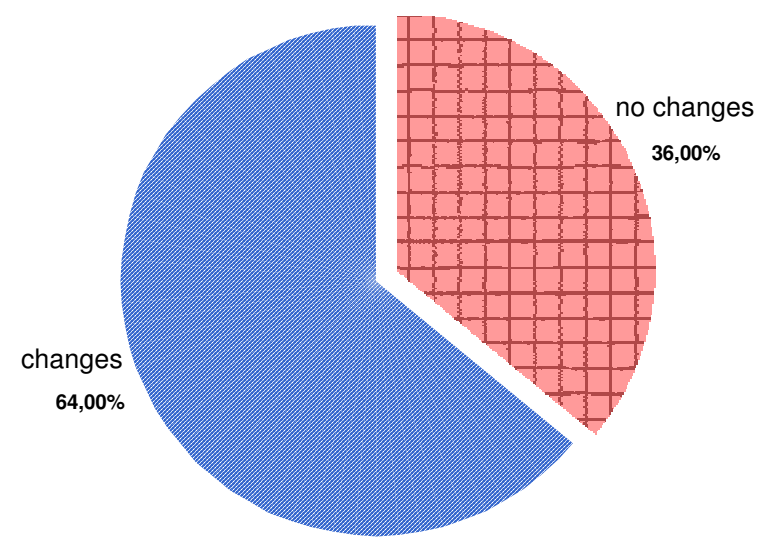

Amongst these, we observe a neat predominance of firms that have enlarged their structure. This suggests some considerations about the implications of technological change on labour. Knowledge is a form of capital (Sacchetti, 2003) which deteriorates over years. Lately, the cycle that includes learning, the creation and use of knowledge has become shorter (the 'lead time of knowledge'). The life cycle of technologies, where technologies represent the application of scientific knowledge, has become shorter and this is particularly evident when thinking about the frequency with which ICTs renew themselves. Rapid changes may create a demand for specific competences. In this case, it seems that the technological change introduced by ICTs has not induced the substitution of labour for technologies. Rather, ICTs have created the space for new 
competences. Amongst the firms which have restructured their organisation by virtue of ICTs, $84 \%$ has enlarged their structure by hiring new personnel.

\section{THE KNOWLEDGE LIFE CYCLE INSIDE THE FIRM}

Our analysis of the production of knowledge introduces a concern about the relationship between knowledge dynamics and local economic systems, and knowledge dynamics inside firms. The answers to our questions - what are the mechanisms and factors that make knowledge capital either grow, consolidate, or decay - require the introduction of a new concept, that of knowledge life cycles, which aims at capturing declining and ascending flows of knowledge within firms and local economic systems.

Resources continuously combine and in so doing they create new value which is a cause of the wealth of nations. Knowledge is one of these resources. Better still, it is knowledge that enables the process of bringing resources together.

More generally we can say that all resources are subject to a process of obsolescence which, over time, diminishes their value. Technologies are changing as well: their equipments, their power engines, and their technique. On technological trajectories (Dosi, 1982) we can count a number of contributions. Economists have been flanked by labour sociologists and psychologists who have enriched literature with contributions on the obsolescence of specific capabilities and of human resources. Less relevance has been instead given to the obsolescence of knowledge per se and to its production context, where by context we refer to the firm or to the territory. Our perspective builds on the idea of knowledge production. ${ }^{5}$ Shifting from physical to knowledge production, we radically change the subject of the analysis.

The knowledge capital of a firm needs to be constantly renewed. Therefore, it requires continuous inward flows of new knowledge. Knowledge flows allow a firm to renew its competences when otherwise competences would reach, at first, the stage of maturity and then they would start a declining phase that would weaken the value added produced by the firm. This would therefore decrease the firm's contribution to the knowledge capital and wealth of its local system.

\footnotetext{
${ }^{5}$ The four phases in the product life cycle theorised by Vernon are linked to consumers' demand for goods. Differently from our perspective, this idea is heavily based on physical production. Cf. Vernon (1966).
} 
We build on two main hypothesis. The first is that although knowledge represents a form of capital which accumulates over time, such capital could not be economically relevant or, in some cases, it could produce distorting effects. The second hypothesis is that, inside the firm or the territory, the accumulation of knowledge does not proceed along a straight trajectory and indistinctively, but it is articulated along different phases, which allow us to advance the hypothesis of a knowledge life cycle.

Figure 4 graphically shows our hypothesis with respect to the knowledge life cycle of firms. It develops along four stages: 1) knowledge acquisition, 2) knowledge sedimentation and adaptation, 3) routine usage of knowledge, 4) knowledge decay.

\section{Figure 6: Knowledge life cycles inside firms and territories}

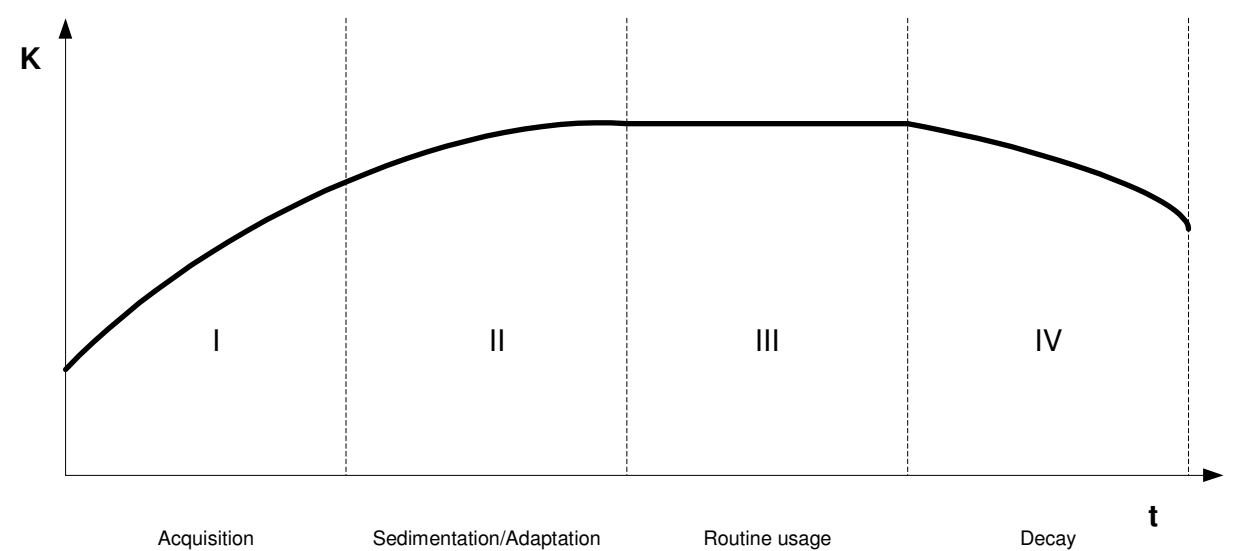

In the first stage, knowledge acquisition, the firm acquires the knowledge which is then incorporated inside physical production in an innovative or differentiated manner. Knowledge acquisition may occur from the outside or the inside. In the first case knowledge can be obtained from three main channels: technology and machineries, human resources, linkages with other firms.

When a firm buys a new machine it appropriates the knowledge incorporated by the machine itself. The firm can then implicitly use this knowledge through physical production. The firm can interact with the knowledge incorporated inside the machinery, causing continuous incremental adjustments which reveal new productive potential. This, for instance, is typical inside industrial districts. 
External knowledge can be obtained also from labour, especially when hiring skilled personnel. In this case the firm appropriates both codified and/or tacit knowledge. An employee without any previous working experience will bring to the firm the codified knowledge that he/she has learned during his/her education. When the educational level of the worker is not very high but the worker has accumulated experience, skills and specific competences, the firm will acquire mainly tacit knowledge. Finally, if an individual has a high educational level and working experience, the firm obtains both forms of knowledge.

Linkages with other firms may represent a third source of external knowledge. One of the objectives that can motivate networking is the circulation or creation of knowledge. Literature has explored equilibriums and risks associated with co-operation and competition when firms transfer knowledge and information (Bettis, Bradley and Hamel, 1992).

Besides external sources, a firm can get new knowledge by creating it internally. As we have mentioned, a characteristic of firms inside industrial districts is the ability to introduce incremental innovations and to continuously adjust their machineries to the needs of production activities.

Furthermore, a firm can internally increase knowledge with respect to human resources. It is the case when the firm organises internal training courses or groupware for managers, or when the tacit transfer of knowledge from the master to the apprentice leads to innovative adjustments.

To end with, firms can rely on internal R\&D centres. Small firms that cannot support a specific internal structure dedicated to research can, nonetheless, assign part of their resources to the development of a new product or process.

After acquisition, the firm moves to the second stage (sedimentation and adaptation) during which knowledge deposits and adapts. At this stage the firm starts to select the knowledge previously acquired on the basis of its strategy and of its expected market positioning. Cognitive layers of knowledge overlap and consolidate to form the intangible capital of the firm. That part of tacit knowledge which is considered strategic is codified. Knowledge is socialised ${ }^{6}$ inside the firm. Moreover, the firm increases the intensity with which it moulds external knowledge according to its specific activities,

\footnotetext{
${ }^{6}$ On the process of knowledge socialisation Cf. Nonaka and Takeuchi (1995).
} 
through machineries, capital, and linkages with other firms. This adaptive function is the most interesting leverage of innovative dynamics. The combination of internal and external knowledge, tacit and codified, may generate new knowledge that is injected in the physical production of goods. At this second stage, knowledge still follows a raising trend which increases the firm's knowledge capital.

At the third stage, routine usage, the firm concentrates on the production process of goods rather than on the production process of knowledge. Knowledge is completely transformed into the physical production of goods. The knowledge that was previously acquired, accumulated and adapted by the firm is now totally consolidated. Tacit knowledge, which has been arranged in the form of codified knowledge, is now part of routines and, consequently, a number of knowledge dimensions are taken for granted. Knowledge routines are then transformed into production routines. The firm exploits the knowledge that has been accumulated during the previous two phases by transferring that knowledge to goods. Usually, during this third stage firms concentrate on process innovation or on a frenetic activity aimed at the reduction of production costs. Knowledge production ceases and the knowledge capital of the firm is temporarily stable. In Figure 4 the curve representing the cycle becomes flatter, physical production prevails over the production of knowledge.

As we mentioned at the beginning of this Section, one of the premises of our theoretical model was that the function of the knowledge accumulated inside the firm could not be an increasing function. In the fourth stage, decay, the knowledge that was accumulated during the first two phases and that was not nourished all through the third stage, becomes obsolete and looses part of its validity. The value added incorporated by the good diminishes and sometimes disappears. In this case the application of the knowledge capital accumulated over years does not represent a convincing barrier and a distinguishing competitive characteristic with respect to potential entrants. Past does not matter anymore. In this situation, changes in competitive dynamics are reflected in the inadequacy of the application of the firm's knowledge capital. Firms facing this phase have two possibilities. They can parch their knowledge capital to focus on cost reduction or they can start producing new knowledge. This means that during the third stage the firm should launch its process of knowledge production either by accessing 
external knowledge or by increasing the resources dedicated to internal production of knowledge.

These four stages describe a hypothetical sequence of situations. Evidences shows that there are firms that, given their age, are still travelling along the first or the second stage at most. There are firms that have been on the declining phase for years but still can keep their market share intact. There are firms that have a long history behind them and that launch continuously the first and the second stage: some amongst these succeed in translating knowledge in physical production, other firms fail, or do not meet consumers' demand with their products. Growing firms suit the first situation in which physical production successfully incorporates the firm's knowledge, whilst the last two situations include firms which are experiencing some difficulties and some of them are closing down.

\subsection{Some empirical evidence}

In our empirical work we have related the age of firms to the presence of an internal $R \& D$ centre. We have then observed that whilst young firms do not include a structure specific for $R \& D$, one quarter of firms born before 1990 undertakes $R \& D$ inside an internal centre.

Table 4: Firms' age and internal R\&D

\begin{tabular}{|ccccc|}
\hline Age & & $\begin{array}{c}\text { Firms with } \\
\text { R\&D centre }\end{array}$ & $\begin{array}{c}\text { Firms without } \\
\text { R\&D centre }\end{array}$ & Total \\
\hline $\begin{array}{c}\text { Firms born } \\
\text { before 1990 }\end{array}$ & Nr. of cases & 33 & 99 & 132 \\
\hline $\begin{array}{c}\text { Firms born } \\
\text { after 1990 }\end{array}$ & Nr. of cases & 1 & 75,0 & 100,0 \\
\hline Total & Nr. of cases & 34 & 20 & 21 \\
& $\%$ & 22,2 & 95,2 & 100,0 \\
\hline
\end{tabular}

Within these two groups of firms, whose distinguishing feature is the year of foundation, firms born in 1900-1939, 1960-1969, and 1980-1989 have the highest frequencies of $R \& D$ centres. 


\section{Figure 7: Relationship between firms'age and R\&D}

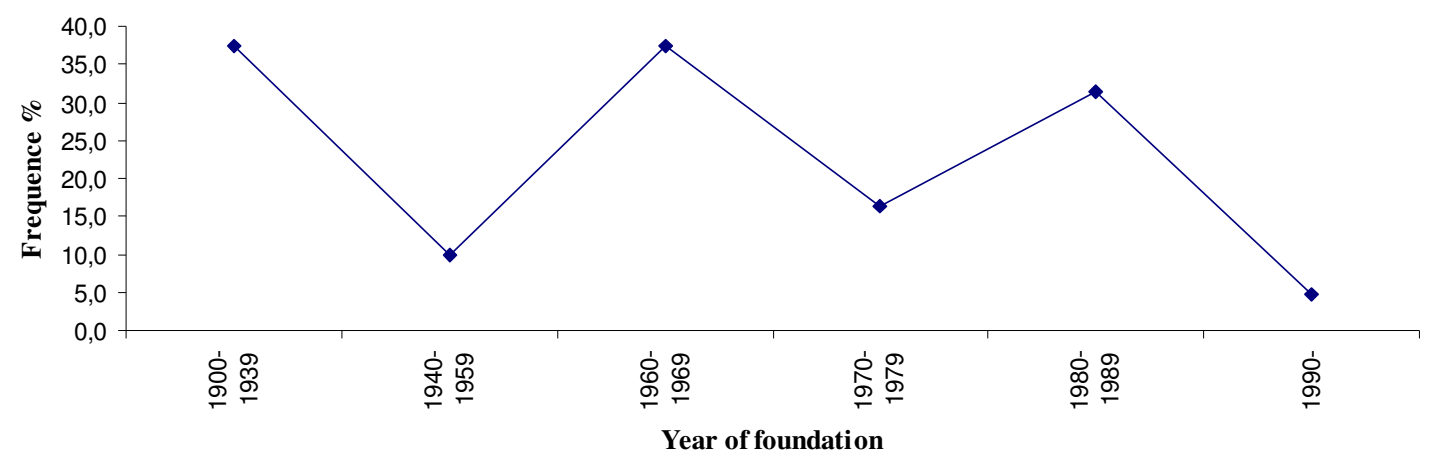

We observe a sort of cycle that describes the presence of firms for which, today, the actual knowledge capital is enriched also by internal $R \& D$ activities. Inside the first class (1900-1939) firms are mainly identifiable with SS and, in particular, with mechanical industry. Amongst firms born within 1960-1969 there are SI and SS sectors with chemical and mechanical firms sized (today) between 100 and 500 employees. The same sectoral characteristics illustrate the type of firms born between 1970-1979, which at present are not so oriented towards organising $\mathrm{R} \& \mathrm{D}$ within a proper internal structure. Between 1980 and 1989 we principally find firms belonging to SI sectors but also firms from SD sectors, which are market leaders in textiles and clothing. More recent firms (from 1990) can be associated with SD sectors (mainly textiles and clothing without leadership roles) or with traditional sectors. Coherently with Pavitt's assumptions, these firms do not rely on internal R\&D.

Our observations suggest that local specific competences which rely today on R\&D were born with producers of specific mechanical components. In parallel, with a more strict focus on products and marketing, sectors such as textiles and clothing that are usually defined as SD but which in this territory are characterised by the presence of leader firms, confer high value added to their production by means of R\&D. Internal $R \& D$, undertaken inside specific centres, seems to be linked to the industrial sector of the firm and, within the sector, to the firm's age. This data suggest that firms (mainly leaders) that have consolidated their structure and their knowledge capital tend to renew and enlarge this capital also through intentionally planned R\&D. 
Further evidences come from an analogous research undertaken in another province (Forlì-Cesena) $^{7}$ where it is shown that for a number of very old firms past is not very important.

Table 5: The importance of past experience (\% of firms for which past is important by size class)

\begin{tabular}{|lc}
\hline \multicolumn{1}{|c}{ Size class } & $\begin{array}{c}\text { Frequency within } \\
\text { size class }(\boldsymbol{\%})\end{array}$ \\
\hline $20-49$ & 25 \\
\hline $50-199$ & 50 \\
\hline $200-499$ & 71 \\
\hline Average amongst classes & $\mathbf{4 9}$ \\
\hline
\end{tabular}

$67 \%$ of firms in the sample assigns an important role to past experience. Medium-large firms are remarkably above the average frequency (71\% of cases). This is probably an indicator that larger firms have more remote origins with respect to smaller firms. The same research results emphasise that experience is perceived as an advantage mainly by firms that are at least thirty-year old. In parallel, the crucial role of the past seems to go in the shade when past becomes particularly far, that is for firms created before the Forties $^{8}$. Knowledge, therefore, becomes cyclical and goes through ascending and descending phases. As other forms of capital knowledge necessitate to be nourished and renewed.

\footnotetext{
${ }_{8}^{7}$ See Appendix B).

${ }^{8}$ The percentage of very old firms who believe that past is not important is higher than for firms that were born between the " $40 \mathrm{~s}$ and ' $50 \mathrm{~s}$.
} 


\section{Figure 8: The importance of past experience and knowledge by firm's age}

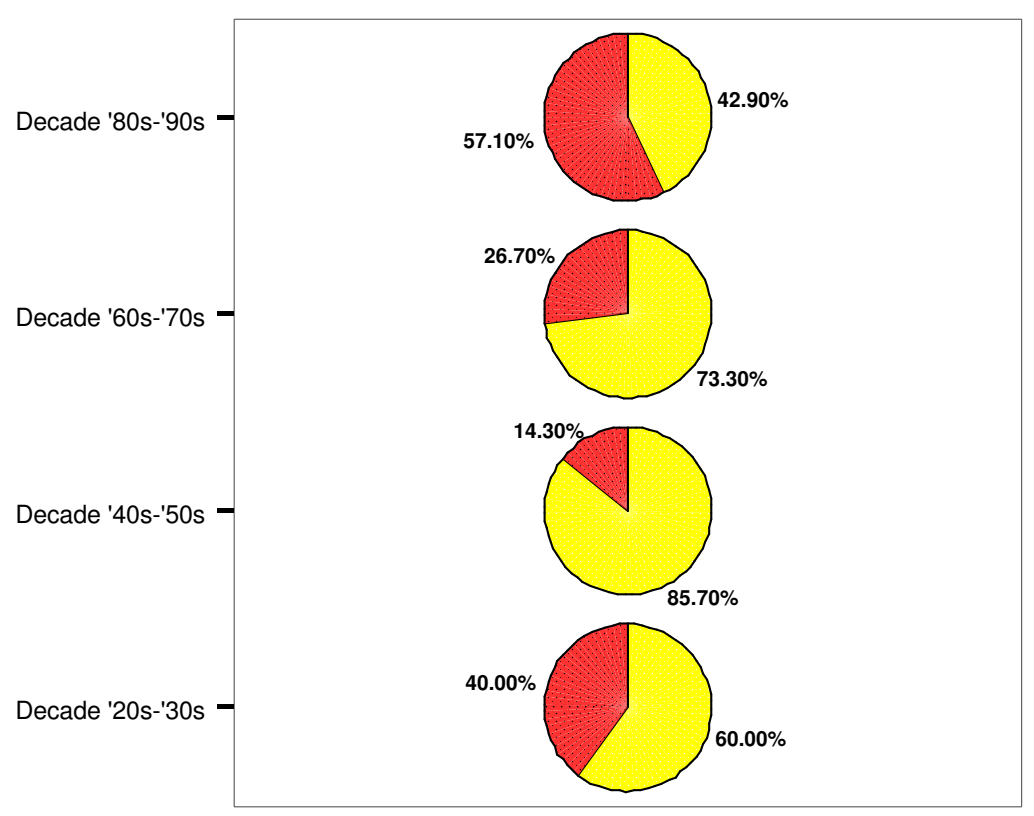

Past

$\square$ Past Important

Past Not important

\section{THE KNOWLEDGE LIFE CYCLE INSIDE LOCAL SYSTEMS}

In the Section 4 we have hypothesised the existence of ascending and descending flows of knowledge inside firms. We have also considered the firm as an open system that interacts with its territory: the firm both appropriates local knowledge and releases knowledge to the territory. Beside knowledge life cycles inside firms, we can design the knowledge life cycle of a territorial system. Of course, production does not take place in a vacuum. The knowledge retained by firms may (or may not) have an impact on the knowledge capital of localities and, vice versa local economic systems influence the extent to which local knowledge can be cumulated over time.

The nature of the knowledge accumulated and rooted inside a locality identifies the peculiar competences of a local production system. The relationship between the knowledge retained by firms and local systems can be, for instance, illustrated by the image of a large firm that, at different points in time, absorbs knowledge from a

\footnotetext{
${ }^{9}$ Bullet points represent firms' positions with respect to the decade of foundation of the firm, the firm size, and the importance given to the past. This figure is based on direct interviews with 34 firms.
} 
territory (for example, in terms of labour) and then releases it outside when increasing, for instance, the knowledge capital of a territory in the form of spin-off firms and new competencies. In this case, the firm works as a "territorial lung": when the firm first settles down it destroys knowledge by absorbing competences when hiring labour, which is a scarce factor for industry especially when it is enriched by highly qualified skills and competences. After that, when the firm starts to interact with the outside system, it can stimulate the establishment of new firms and competencies. For instance, it can encourage education and learning, co-operate with other firms for the introduction of innovation, stimulate knowledge diffusion together with other territorial actors such as Universities.

This exchange between the firm and its territory is one of the factors that helps the firm to renew its knowledge and the local system to follow the evolution of techniques and production modalities. Scientific and technological knowledge continuously develops following cyclical patterns. This process decrees the obsolescence of the knowledge capital of firms, from the knowledge incorporated inside technologies, to tacit knowledge that is embodied by individual competences and skills, to the knowledge included into organisational routines.

\section{Figure 9: The "territorial lung"}

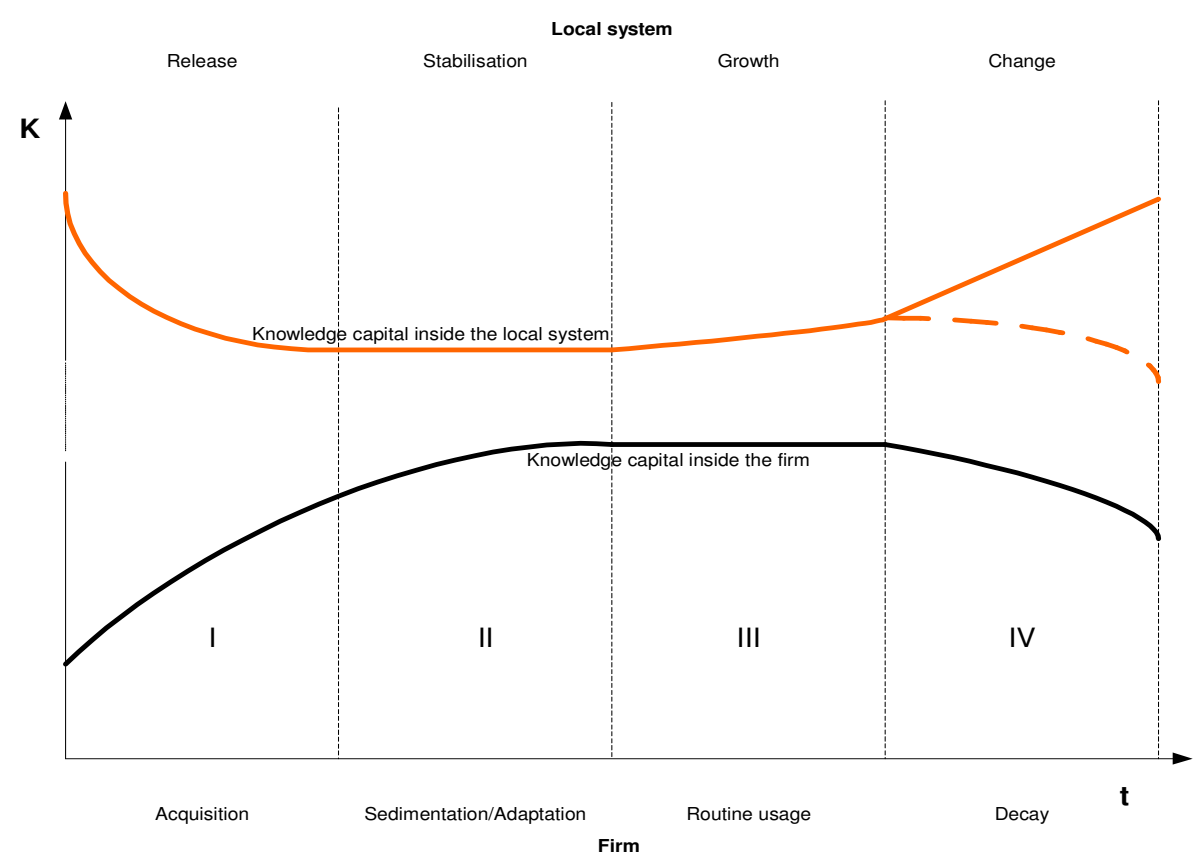


Figure 6 presents, besides the knowledge life cycle of the firm, the knowledge cycle inside the territorial system. We hypothesise, considering a large firm, the existence of an interaction between a firm's dynamics and the local system. ${ }^{10}$

Suppose a situation in which a large firm settles within a territory characterised by a rich knowledge capital. For the large firm a territory may represent a potential of knowledge for three main reasons essentially. A territory is a potential of tacit knowledge if a network of small or craft firms already exists as this network can be represent an input of contextual knowledge and of specific learning capacity within a particular industrial sector. Furthermore, a territory is a potential of codified knowledge if it includes vocational schools, faculties or university degrees that have contributed over time to diffuse knowledge amongst local people. Finally, a territory is a potential of tacit and codified knowledge which is diffused amongst local institutional actors, within their routines, policies and development programmes, their governance capacity to promote the social and economic development of the community. These three factors, which may vary extremely between territories, represent the whole knowledge potential that is directly or indirectly appropriable by a large firm when it settles down.

When a large firm is established we are in the first stage of the cycle, which corresponds to knowledge acquisition for the firm and to a reduction of knowledge for the territory. The firm will need specialised competences. It is possible that craftsmen will leave their own activities and accept to become employees, a position that would guarantee a fixed salary to them. Some small firms could orient their production towards the needs of the large firm and become subcontractors producing for a single main prime-contractor. Their incremental innovative capacity will serve the adjustments required by the large firm. People coming from vocational schools and Universities will be absorbed by the large firm, thus jeopardising entrepreneurship forces inside the local system. To sum up, this first stage is characterised by a sort of internalisation of territorial knowledge inside the firm.

In the second stage, the large firm starts to deposit knowledge and transform the tacit knowledge it has acquired into codified knowledge and production routines. Gradually, the appropriation of territorial knowledge slows down.

\footnotetext{
${ }^{10}$ Our analysis, as it is, is not applicable to small firms entry or systems of small firms. Nor is it appropriate with respect to the entrance of a large firm inside a system with a poor knowledge capital.
} 
The third stage is characterised by the application of knowledge to physical production. The firm consolidates and grows, whilst the absorption of local knowledge stops.

In the fourth phase, the firm starts to release and diffuses knowledge inside the local system. This is the stage in which the firm externalises its knowledge. This happens, for instance, when spin-off processes (more or less encouraged by the large firm) are activated within the territory, when the firm financially support schools or universities and promotes training courses. Finally, an extreme situation that has been however quite frequent for industrial districts, is when the firm goes bankrupt and releases knowledge on the territory. Specialised workers loose their job and - having access to a sufficient financial capital - may become entrepreneurs and start their own activity, generating a small industrial district. At this stage, the firm releases and therefore looses knowledge, whilst the territory increases its knowledge capital.

These two knowledge cycles last over time, waving in opposite directions with different intensity. The intensity of the osmotic function of knowledge between the firm and the territory is linked to the nature of the firm (whether transnational or multinational), to its industrial sector, to the capacity of territorial actors to manage such a process.

\section{CONCLUSIONS}

In this paper we have provided some theoretical insights on the production of knowledge and on the role of knowledge in physical production. Our main finding is that knowledge does not always grow following a cumulative process, but it can evolve or stagnate and, if not renewed, it can be subject to a process of decay. This evolutionary perspective relates both to the firm and to its local system, where the two continuously interact by providing or absorbing knowledge the one from the other. Firms' production decisions, in particular, crucially influence ascending and descending flows of knowledge within their organisation and the territory. The territory, in parallel, can accelerate the dynamics of knowledge by proactively favouring interactions and cooperation with outside systems and by supporting a context where knowledge can be transmitted and diffused amongst economic actors.

When economic systems go through phases of structural uncertainty, firms must be able to promptly adapt to new situations at such a speed that the distinction between present 
and future becomes blurred. On the face of it, according to the way knowledge is organised, created, transferred and diffused inside and amongst firms and between firms and other institutional actors, local economic systems can provide more or less convincing answers to structural uncertainty. Moreover when local actors co-operate and communicate, knowledge is proactively created and diffused also outside firms, thus providing to the local industry the tools to interpret structural uncertainty and, sometimes, to anticipate continuously changing events.

When a new large firm begins a process of interaction with the territory in which knowledge is exchanged territorial knowledge could, over time, either grow or fall down. As we have mentioned, interaction could, for instance, focus on education and training programmes, or diffused processes of technological change. There are, however, other situations that can lead to radically different results. A firm can be opened to knowledge inputs coming from the territory but may be closed with respect to outgoing flows of knowledge. In this situation the local system does not receive knowledge inputs from the firm and thus cannot increase its capital stock. The firm has accumulated new knowledge, whilst at same time destroying pieces of local knowledge.

APPENDIX

\section{A) Reggio Emilia empirical data: sample and methodology}

Our universe of firms was formed by manufacturing firms with more than 10 employees. $34 \%$ of firms in the sample are above 50 employees and include $87 \%$ of employees in the sample. We have collected data in 2001 using a structured questionnaire that was sent to 1900 firms. Questionnaires were submitted to the entrepreneurs/owners or to chief directors. 168 questionnaires were returned, mainly from manufacturing sectors. The average dimension of firms in the sample is 108 employees. When using Pavitt's categories, we have used, with minor adaptations, the classification from OECD STAN database for industrial analysis.

\section{B) Forlì-Cesena empirical data: sample and methodology}


The sample includes 80 firms, of which 47 have more than 50 employees. Data have been collected in the year 2000 through postal questionnaires and direct structured interviews with entrepreneurs.

\section{References}

Bettis, R. A., S. P. Bradley and G. Hamel (1992), "Outsourcing and industrial decline" Academy of Management Executive, 6(1): 7-22.

Braverman, H. (1974), Labour and Monopoly Capital. The Degradation of Work in the Twentieth Century, Monthly Review Press, New York.

Babbage C. (1832), On the Economy of Machinery and Manufactures, London.

Dosi, G. (1982) "Technological Paradigms and Technological Trajectories: a Suggested Interpretation of the Determinants and Directions of Technical Change”, Research Policy, 2 (3): 147-62.

European Commission, Agenda 2000.

Ferguson A. (1767), An Essay on the History of Civil Society, D. Forbes (ed), Edinburgh 1966.

Kern, H. e Schumann, M. (1984), Des Ende der Arbeitsteilung?, Werlag Bech'sche, Munchen; Italian translation: La fine della divisione del lavoro?, Einaudi, Torino, 1991.

Marx, K. (1867), Das Kapital. Kritik der Politischen Ökonomie.

Nonaka I. and Takeuchi H. (1995), The Knowledge-Creating Company, Oxford University Press, Oxford.

Pavitt, K. (1984) "Patterns of Technological Change: Towards a Taxonomy and a Theory", Research Policy, 13(6): 343-74.

Polanyi, M. (1958) Personal Knowledge. Toward a Post-Critical Philosophy, Routledge \& Kegan Paul, London.

Poma L. (2003) Oltre il distretto. Imprese e istituzioni nella nuova competizione territoriale, Franco Angeli, Milano.

Pollock, F. (1957) The Economic and Social Consequences of Automation, Oxford: Basil Blackwell. 
Sacchetti, S. (2003) "Knowledge as capital. How the organisation of production impacts on local development", Working Paper No. 4 (April), University of Ferrara, Department of Economics, Institutions and Territory.

Sacchetti, S. and Sugden, R. (2003), "The Governance of Networks and Economic Power: the Nature and Impact of Subcontracting Relationships" Journal of Economic Surveys, 17(5), forthcoming .

Schumpeter, J. A. (1912), Theorie der wirtschaftlichen Entwicklung, Duncker \& Humblot, Leipzig; English translation: The Theory of Economic Development, Harvard University Press, Cambridge Mass. 1934; reprinted by Transaction Publisher, New Brunswick 1996.

Smith A. (1994), An Inquiry into the Nature and Causes of the Wealth of Nations (1776), The Modern Library, New York.

Stiglitz, J., (1987) "Learning to Learn, Localised Learning and Technological Progress" in Dasgupta P. and P. Stoneman (eds.) Economic Policy and Technological Performance, Cambridge University Press, Cambridge.

Vernon, R. (1966), "International Investment and International Trade in the Product Cycle" Quarterly Journal of Economics, 80(2): 190-207. 